\title{
Repensando el Currículum desde una visión integrada: "El Humanities Curriculum Project" para una escuela democrática
}

Recibido: 8 de junio de 2018 / Revisado: 12 de junio de 2018

Aceptado: 13 de junio de 2018 / Publicado: 12 de julio de 2018

MORCILLO, LORO, VIRGINIA

Departamento Educación,

Universidad Internacional de la Rioja, España

morcillo@unir.net

GUTIÉRREZ SÁNCHEZ, JOSÉ DAVID

Departamento de Trabajo Social y Servicios Sociales,

Universidad Pablo de Olavide, España

jdgutsan@upo.es

DIZ CASAL, JAVIER

Departamento de Antropología Social, Universidad de Vigo, España

jdizca@hotmail.es

\section{RESUMEN}

En el presente trabajo reflexionamos sobre la necesidad de repensar el currículum escolar, desde una perspectiva integrada, para la construcción de una escuela justa socialmente y democrática. Para ello, nos servimos del Humanities Curriculum Project, de Lawrence Stenhouse, con la finalidad de revalorizar su sentido en la educación actual, del siglo XXI. Se trata de avanzar en propuestas curriculares que tomen como base los tintes del currículum humanista para una escuela que se adapta a las características particulares de su estudiantado y desde un modelo centrado en el aprendizaje. El núcleo central de este currículum radica en presentar temas controvertidos tratados

\section{ABSTRACT}

Rethinking the Curriculum from an integrated vision:

“The Humanities Curriculum Project” for a democratic school

In the present work we reflect on the need to rethink the school curriculum, from an integrated perspective, for the construction of a socially and democratically just school. For this, we use the Humanities Curriculum Project, by Lawrence Stenhouse, in order to revalue its meaning in the current education of the $21 \mathrm{st}$ century. It is about advancing in curricular proposals that take as a base the dyes of the humanistic curriculum for a school that adapts to the particular charac- 
desde el diálogo, protegiendo la divergencia de los puntos de vista del alumnado. Al enfocar el conocimiento tomando como referentes la líneas humanista e integrada acercamos a los y las estudiantes a una mayor comprensión y análisis de las injusticias sociales, favoreciendo una concienciación crítica ante un sistema (a veces) desigual. En definitiva, conjugamos la visión integrada del conocimiento junto a la perspectiva democrática y humanística en la educación, para tratar de dar respuestas a las demandas de un alumnado que así nos lo reclama.

PALABRAS CLAVE: Curriculum educativo, curriculum integrado, escuela democrática. Humanities Curriculum Project. teristics of its students and from a model focused on learning. The core of this curriculum lies in presenting controversial issues treated from the dialogue, protecting the divergence of the points of view of the students. By focusing on knowledge, taking humanistic and integrated lines as references, we bring students closer to a greater understanding and analysis of social injustices, favoring critical awareness. In short, we combine the integrated vision of knowledge with the democratic and humanistic perspective in education, to try to respond to the demands of a student who demands this.

KEYWORDS: Educational Curriculum, Integrated Curriculum, Democratic School. Humanities Curriculum Project.

\section{Introducción}

Al atisbar la educación en tiempos contemporáneos (García-Lastra, 2013), bajo un emplazamiento donde lo líquido (Bauman, 2006) se torna incuestionable y lo incierto fluye (Fernández Enguita, 2001), emerge un requerimiento inquebrantable: El conocimiento escolar (Bernstein, 1996; Feuerstein, 2006; Velasco, 2007; Villalta, Assael y Martinic, 2013; Villalta y Martinic, 2009) y ante él múltiples interrogantes: ¿Cómo es el conocimiento que se enseña? ¿Quién lo selecciona? ¿Cómo se implementa en la práctica? ¿Qué se tiene en cuenta? ¿Por qué sigue considerándose como un debate abierto? Nuestro cometido no consiste en atribuir réplicas a tales hipótesis, tratamos - en otro sentido - de ofrecer una visión del currículum que atesore las nuevas demandas a las que se yuxtapone la institución educativa en este siglo coetáneo. Escudriñamos la necesidad de proyectar o visibilizar un currículum al amparo de procesos sociales, democráticos, justos, educativos e interculturales para dar respuesta a los emergentes desafíos educativos de esta era global o, en palabras de Giddens (2005) para un "mundo desbocado". En este breve espacio merece la pena recordar lo que decía el dramaturgo Eugène Ionesco:

El hombre moderno, universal, es el apurado, no tiene tiempo, es prisionero de la necesidad, no comprende que algo pueda no ser útil, no comprende tampoco que, en el fondo, lo útil puede ser un peso inútil, agobiante. Si no se comprende la utilidad de lo inútil, la inutilidad de lo útil, no se comprende el arte. Y un país donde no se comprende el arte es un país de esclavos o de robots (...) esa gente atareada, ansiosa, 
que corre hacia una meta que no es humana o que no es más que un espejismo puede, súbitamente, al sonido de cualquier clarín, al llamado de cualquier loco o demonio, dejarse arrastrar por un fanatismo delirante, una rabia colectiva cualquiera, una histeria popular. Las rinocerontitis más diversas, de derecha y de izquierda, constituyen las amenazas que pesan sobre la humanidad que no tiene tiempo de reflexionar de recuperar su serenidad o su lucidez. (Citado en Ordine, 2013, p. 74)

Como ya señalaron de manera premonitoria, Macionis y Plumer, en la década de los 90, "no cabe duda que la escuela del siglo XXI será distinta de la que hoy conocemos" (Macionis y Plumer, 1991, p. 523). Tal consideración no hace más que certificar que los problemas del mundo contemporáneo se hacen extensibles al campo educativo. Por tanto, nos encontramos en la tesitura de repensar el sentido de la escuela y de forma paralela el planteamiento curricular. Retomamos el sentido del Humanities Curriculum Project por su base democrática y humanista, por la necesidad de razonar el conocimiento desde la acción, de forma deliberada y consensuada. La realidad gravita en la búsqueda de mecanismos donde el colectivo docente pueda incorporar en la cotidianeidad de su aula la experiencia del alumnado, desde el tratamiento de las desigualdades e injusticias sociales que azotan a la aldea global. Se trata de buscar fórmulas transgresoras que escapen al control técnico e ideológico del poder dominante. Tal como lo sugiriera Freinet (1970), perseguir una teoría renovada en la que los docentes se encuentren en las condiciones idóneas para crear su propuesta.

La matriz del Humanities Curriculum Project reside en el tratamiento de temáticas controvertidas desde la reflexión y salvaguardando las diferentes miradas del alumnado ante ellas. Su desarrollo, experimentación, investigación e implementación; desde un posicionamiento integrado, proporcionará al estudiantado una visión real y analítica en torno a los diferentes "atropellos" sociales. A la postre, evidenciamos su aportación al campo educativo y al estudio del currículum escolar desde las demandas de un alumnado que así lo reclama. En definitiva, dibujamos su relevancia para la construcción de una institución educativa justa y democrática.

\section{La epistemología en la educación actual: un debate abierto sobre los saberes fundamentales}

El término "epistemología" deriva del griego <episteme> que significa conocimiento, y es una rama de la filosofía que se ocupa de todos los elementos que procuran la adquisición de conocimiento e investiga los fundamentos, límites, métodos y validez del mismo (Ceberio y Watzlawick, 1998). Las preguntas pertinentes desde las que se podría arrancar el sentido del conocimiento en el ámbito escolar, bajo la necesidad de explorar alternativas en el caso de la selección de los aprendizajes que van a formar parte del currículum educativo, podrían ser: ¿qué deben aprender los escolares a lo largo de la educación obligatoria? 
¿Qué contenidos se seleccionan en la escolaridad? ¿Esa selección de contenidos garantiza un aprendizaje relevante en el alumnado? ¿La experiencia escolar se ha de considerar? El punto de partida para dotar de respuestas coherentes a tales interrogantes lo tomamos de Gimeno Sacristán (2008) al considerar que "los contenidos no son metas, sino materiales para hacer competentes a quienes aprenden” (p.8).

Las polémicas en torno a los contenidos escolares conforman el debate por excelencia de la educación. El debate se enrarece al entremezclar la división del conocimiento en disciplinas, junto a la acumulación memorística de información tan acuciada, cuanto no menos descuidada, en el terreno educativo. Autores como Dewey (1989), Pozuelos, Romero, García y Morcillo (2010), Hernández y Sancho (1989), rechazan que el contenido del currículum se presente a través de la parcelación académica y disciplinar del saber científico y que ese sea el punto de partida de la enseñanza. El resultado de esa excesiva compartimentalización de la cultura en asignaturas, temas, lecciones, conlleva una "sobrecarga de fragmentos inconexos, sólo aceptados basándose en la repetición o autoridad” (Dewey, 1989, p. 159), y que los escolares, para sobrevivir en las aulas, han de acumular en sus mentes. Desde esta perspectiva, tal como reitera García (2007) podemos "cuestionar el referente científico-disciplinar como referente único o principal del conocimiento escolar" (p. 487). Esto no quiere decir que el conocimiento científico no esté presente, sino que deberíamos enseñar, como plantea Rozada (2001) “un conocimiento tan disciplinar como sea necesario para que no sea meramente vulnerable, pero a la vez tan 'indisciplinado' como sea preciso para que llegue a conectar con los alumnos y su mundo; y, al mismo tiempo, tan práctico como haga falta para que no sea sólo repetido en situaciones de examen" (p. 5).

Por otra parte, en el debate sobre la naturaleza del conocimiento escolar intermedian como elementos necesarios, por su estrecha relación, diferentes arquetipos del conocimiento: científico, ordinario o cotidiano. Éste último conocimiento es el que nos acerca al bagaje experiencial del alumnado y, es desde este conocimiento sobre el que hemos de dirigir las miradas. Tal idea conlleva plantear la necesaria redefinición del currículum como espacio para la participación, en el que la voz de los estudiantes se torna como imprescindible. Consultar a los alumnos supone cambiar las relaciones jerárquicas, los maestros vencen sus miedos y límites y abordan sus relaciones conflictivas con los escolares, quienes necesitan destrezas y familiaridad en el entorno de comunicación con una buena relación con el docente (Martínez, 2010). Para ello es recomendable, como primer requisito, "interpretar y representar las experiencias de los estudiantes, desde sus mismas perspectivas e identidades" (Martínez, 2010, p. 171). Autores como Cook-Sather (2007); Thiessen y Cook-Sather (2007) proponen traducir nuestra comprensión de los términos que evocan los estudiantes: sus ideas, identidades, roles y esquemas para comprender sus experiencias como alumnos.

El carácter integrador y complejo de la perspectiva de la didáctica obliga a tener en cuenta, conjuntamente, todas estas dimensiones, a establecer relaciones entre ellas y a elaborar una hipótesis de trabajo 
que oriente la intervención educativa (García, 2001). Si traemos a colación el movimiento curricular de los años 60 y 70, en el que el Humanities Curriculum Project de Stenhouse y el curriculum MAN: A Course of Study de Bruner ${ }^{1}$ se encontraban inmersos, tal movimiento actuaba de acuerdo con la "hipótesis de que la renovación de los contenidos de la enseñanza sólo se podía lograr desarrollando el arte del profesor de manera que fuera posible llevar a cabo modos de aprendizaje basados en la discusión, el descubrimiento y la investigación" (Stenhouse, 1991, p. 14). Destacando como eje prioritario para la mejora del conocimiento el papel del docente como investigador.

En aras de abrir puertas al tratamiento de los contenidos como nutrientes de las competencias, se requiere que en el texto curricular se seleccionen contenidos relevantes y se articulen según, al menos los siguientes principios que los harán más educativos (Gimeno Sacristán, 2005):

1. Consideración amplia de los contenidos esenciales y relevantes de los diferentes campos culturales del saber, la tecnología, las artes y las formas de expresión y comunicación.

2. Considerar las materias en la medida de lo posible como territorios controvertidos.

3. Establecer las conexiones interdisciplinares posibles entre las áreas y asignaturas.

4. Desarrollar competencias transversales, como la lectura, los hábitos de trabajo. En todas las áreas se debe leer e interpretar textos.

5. Que capaciten para el conocimiento y análisis de las variadas actividades y modos de vida.

6. Concienciación sobre temas y problemas que afectan a todos en un mundo globalizado: el orden mundial, el hambre, el agotamiento de los recursos, la emigración...

7. Adoptar una perspectiva pluricultural en todos los contenidos cuando sea posible, para transmitir un sentido de la cultura como un crisol mestizo de múltiples aportaciones y concienciar acerca de la diversidad humana, base del respeto y tolerancia a las diferencias.

8. Analizar y valorar las contribuciones más señaladas al progreso humano.

9. Extraer de la narrativa acerca de la ciudadanía en democracia contenidos y directrices para cualquier asignatura, para cualquier docente y para cada acción. (pp. 117-118).

10. En definitiva, el currículum es la vía para garantizar una educación inclusiva y equitativa de calidad y promover oportunidades de aprendizaje permanente para todos, según el objetivo de de-

1 Bruner consideraba que era posible enseñar a los niños y a las niñas a ser más humanos y eliminar el racismo y el etnocentrismo al estudiar de cerca otra cultura. Al mismo tiempo, creía que podemos enseñarles ideas complejas a los alumnos empleando el método del "currículum en espiral" que introduce el mismo tema al aumentar la complejidad a lo largo de un período de tiempo. 
sarrollo sostenible 4 (ODS 4) de la UNESCO. El currículum ha de contemplar los mecanismos necesarios para maximizar el potencial para la mejora del aprendizaje, brindando oportunidades en la vida y ofreciendo un sentido práctico a un compromiso de inclusión, desde el desarrollo profesional docente.

\section{Hacia una visión integrada del conocimiento desde una perspectiva democrática}

En su origen, el currículum significó el espacio acotado y regulado del conocimiento que representa los contenidos que los docentes y los centros educativos tendrán que desarrollar. De todo lo que sabemos y es potencialmente enseñable y posible de aprender, el currículum es una selección regulada de los contenidos a enseñar y aprender que, a su vez, regulará la práctica educativa que se desarrolla durante toda la escolaridad (Gimeno Sacristán, 2010). A su vez, Bernstein (1996) señalaba que el currículum lo conforma todo lo que ocupa el tiempo escolar, considerándose algo más que lo que tradicionalmente se viene aceptando como contenidos de las distintas materias escolares.

Sin embargo, actualmente, se acepta y se critica que los escolares en las instituciones de educación formal están adquiriendo demasiados aprendizajes inertes, superficiales, mecánicos, artificiales, fragmentarios, con escaso sentido y descontextualizados (Ausubel, 2002; Darling-Hammond, 2001; Perkins, 2010). Una de las piedras de toque centrales es que vivimos inmersos dentro de la sociedad de la información, la cual, a su vez, está dando lugar a una nueva concepción, cultura del aprendizaje (Pozo, 2008). Dentro de esta cultura del aprendizaje, estamos obligados a lidiar con grandes cantidades de información para transformarlas en conocimiento útil, significativo y relevante; a pesar de ello, paradójicamente nos encontramos poco preparados para asumirlo, porque, mientras vivimos en una sociedad en la que estamos inundados de información, al mismo tiempo vivimos una educación desfasada, caracterizada por prácticas educativas de sabor añejo que poco preparan al estudiante para que éste adquiera las herramientas necesarias que le permita aprender de forma reflexiva y crítica (Hernández y Díaz, 2013).

Pero, ¿qué está ocurriendo? ¿Hacia dónde hemos de avanzar? En palabras de Feito (2010):

La escuela que tenemos responde a una sociedad industrial en la que las personas tenían la expectativa de que los conocimientos adquiridos en la escuela serían suficientes para desenvolverse en la vida laboral. Aquí cobra sentido el modelo de repetir y memorizar. Sin embargo, hoy en día el aprendizaje a lo largo de toda la vida y la predisposición a afrontar cada vez más imprevistos resultan clave. (p. 55) 
La educación obligatoria ha de tener como propósito educar a sus alumnos para un mundo en constante cambio, desde el diálogo y la democracia en la práctica educativa. Aspiramos a edificar una escuela capaz de construir ciudadanos participativos, críticos, responsables. Estudiantes con afán de seguir formándose y cultivando, cultural y educativamente, a lo largo de su trayectoria vital y con espíritu innovador. Con profesores que transgredan las formas tradicionales de la educación. Para ello se requiere que el currículum se plasme en un texto que contemple la complejidad de los fines de la educación y desarrollar una acción holística capaz de despertar en los escolares procesos que sean propicios para alcanzar tal propósito. Entre ello se encuentra (Gimeno Sacristán, 2010):

i) Ensanchar las posibilidades y referentes vitales de los individuos, partan éstos de donde partan. Crecer y abrirse a mundos de referencia más amplios es una posibilidad para todos, aunque lo sea de manera distinta y en desigual medida; ii) hacer de los menores ciudadanos solidarios, colaboradores y responsables, provocando el que tengan las experiencias adecuadas, siendo reconocidos como tales ciudadanos mientras se educan; iii) fundamentar en ellos actitudes de tolerancia en el estudio de las materias mismas, lo que implica la transformación de éstas; iv) afianzar en el alumnado principios de racionalidad en la percepción del mundo, en sus relaciones con los demás y en sus actuaciones y; v) hacerle consciente de la complejidad del mundo, de su diversidad y de la relatividad de la propia cultura, sin renunciar a valorarla también como "suya" la de cada grupo, cultura, país, modo de vida... (pp. 31-32)

Tras este ideal, encontramos la otra cara de la moneda, las prácticas escolares que se vienen realizando en las últimas décadas, salvo contadas excepciones, acostumbran a regirse por el esquema simplista de unos docentes que saben mucho y unos escolares que apenas saben nada y que, por consiguiente, necesitan aprender mediante la enseñanza toda una serie de contenidos asociados a disciplinas o asignaturas inconexas, con denominaciones tales como: matemáticas, lenguaje o educación física. Todo ello, al abrigo de una estrategia metodológica muy condicionada por materiales curriculares como los libros de texto o guías, así como de un sistema de evaluación reducido casi exclusivamente a lo que conocemos como exámenes o pruebas escritas que avalan ante el resto de la sociedad los méritos y deméritos alcanzados por el discente (Torres, 2005).

Para suavizar este panorama aparece la perspectiva constructiva. Ésta centra su enseñanza en el alumno, subordina las secuencias de contenidos y las metodologías didácticas a los principios de individualización y funcionalidad del aprendizaje, además supone al docente el papel de mediador del currículum y, por otra parte, proporciona el ajuste de las distintas modalidades de ayuda pedagógica a las necesidades de sus alumnos. Sin embargo, en tal exposición, nos centramos en una de sus particularidades, las cuales nos conducen hacia la comprensión y la interpretación de la práctica educativa de acuerdo 
a una serie de principios (Ortega, Luque y Cubero, 1997). Éstos ayudan a contemplar la enseñanza de unos contenidos en torno a un proceso que se construye, así como:

- Principio I. Todo cambio en la organización cognitiva es una construcción personal del alumno a partir de experiencias de aprendizaje en las cuales pone en juego sus capacidades y las amplía.

- Principio II. Lo que se construye a través de la educación escolar son capacidades relacionadas con el conocimiento y uso de contenidos culturales.

- Principio III. El proceso de construcción de los contenidos culturales se realiza con la ayuda contingente de otras personas con más experiencia cultural, que facilitan dicha construcción.

- Principio IV. El contexto influye en la construcción de conocimientos y capacidades porque da sentido a la experiencia.

- Principio V. La construcción del conocimiento escolar es una función de la ayuda prestada contingentemente a las necesidades educativas del alumno.

- Principio VI. Se aprende lo que se comprende.

- Principio VII. El pensamiento autónomo se construye a partir del diálogo y la toma de conciencia.

- Principio VIII. Hay muchas maneras de aprender, pero el modo de aprender no cuestiona los supuestos epistemológicos básicos. (Ortega, Luque y Cubero, 1997, pp. 313-336)

Nada más alejado de la realidad o de este ideal, seguimos siendo espectadores de un escenario en el que los conocimientos seleccionados como imprescindibles y relevantes caen en manos de una "hegemonía dominante, convirtiéndose en un verdadero obstáculo para la consecución del éxito escolar de todos y todas" (Feito, 2011, p. 28). En palabras de Jurjo Torres (2010):

Los nuevos lenguajes educativos tecnocráticos están siendo utilizados como estrategia para desviar la atención sobre los contenidos culturales verdaderamente relevantes y necesarios para entender y participar en las modernas sociedades. La cultura política dominante vive obsesionada por los resultados de las evaluaciones comparativas internacionales, lo que sirve para desplazar las miradas sobre qué contenidos escolares realmente merecen la pena y cuáles son más secundarios o inapropiados e incluso injustos. (p. 99)

Las escuelas se vehiculan en torno a una espiral de evaluaciones externas o estandarizadas, en la que los resultados escolares ocupan su más sentido "lugar". En algunos casos, los centros educativos despliegan todas sus herramientas para emprender acciones en las que obtener logros exitosos en los 
resultados académicos y de la propia institución educativa. Todo ello deriva en una competición internacional por ver qué equipo consigue la pole-position. Cierto es, que llega a ser tal la preocupación que la política educativa ha vertido en los centros escolares, que la selección adecuada de unos contenidos culturalmente válidos — a día de hoy - , aparecen en un segundo plano.

El dilema o debate surge cuando nos planteamos cómo trabajar esos contenidos con nuestros escolares. Abocados al memorismo, los alumnos olvidan con facilidad los contenidos y rara vez o, en ocasiones contadas, son capaces de aplicarlos a situaciones reales e incorporarlos a sus esquemas interpretativos de la realidad.

En este sentido, el papel del docente es fundamental, en la selección de unos determinados contenidos, para ello, Klafki (1958) selecciona cinco preguntas adaptadas a ese propósito:

- ¿De qué profundo o general sentido de la realidad es ejemplo? ¿Qué fenómeno o principio fundamental, ley, criterio, problema, método, técnica o actitud se puede captar utilizándolo como ejemplo?

- ¿Qué significado previo puede tener este concepto para el alumnado de mi clase? ¿Qué significado puede tener desde un punto de vista pedagógico?

- ¿Qué aporta para el futuro de mis alumnos?

- ¿Cómo se estructura pedagógicamente?

- ¿Qué hechos, fenómenos, situaciones, experimentos, controversias, intuiciones... son apropiados para inducir al alumnado a plantear preguntas dirigidas a la esencia y estructura del contenido en cuestión? ¿Qué imágenes, indicaciones, relatos, situaciones, observaciones, experimentos, modelos... son apropiados para ayudar al alumnado a responder de la manera más autónoma posible las preguntas dirigidas a los aspectos esenciales del tema? ¿Qué situaciones y tareas son apropiadas para ayudar al alumnado a captar lo principal del tema mediante un ejemplo o un caso elemental, y para aplicarlo y practicarlo de manera que le resulte útil? (p. 45)

La labor de los maestros y de las maestras en la selección del conocimiento escolar requiere de un trabajo riguroso en el que formularse interrogantes continuamente. Sólo desde la reflexión y deliberación, así como del análisis de aquellos contenidos realmente válidos para el alumnado, se acercará a las nuevas demandas que la educación de hoy necesita. Esto es un hecho. Pero, ¿cómo superar esa dicotomía entre la selección de unos determinados conocimientos y su forma de integrarlos en la estructura cognitiva de los estudiantes? Es trabajando con estructuras de contenidos más interdisciplinares como favorecemos que el estudiante, a diario, aprenda a hacerse preguntas más complejas; que no le tenga miedo a experimentar, a explorar por nuevos caminos que esos saberes con los que entra en contacto le 
va abriendo. Es de esta manera como mejor podemos garantizar una auténtica educación de personas democráticas, reflexivas y críticas (Torres, 2010). Torres (2010), al mismo tiempo, coincide con el planteamiento de John Dewey, el cual, defendió en su tiempo que las instituciones escolares deben involucrar al alumnado en una constante investigación e interrogación de la realidad en la que vive, de los asuntos humanos que preocupan en cada momento. Esta aseveración, como analizaremos más adelante, coincide con el planteamiento del Humanities Curriculum Project.

La interpretación o traducción compartida ayuda a redefinir los roles de profesor o alumno, a comprender las posibilidades y límites de la escuela, cambiar los focos de atención y los esquemas de interpretación en la relación adultos y escolares, abrirse a lo inesperado o inaceptado, sin considerarlos un grupo uniforme (Martínez, 2010). Martínez Bonafé (2004) advierte que "el currículum es la herramienta cultural con que la escuela capacita al sujeto ciudadano para protagonizar la vida democrática en un sentido pleno. Al pensar en los componentes de un currículum democrático deberíamos entender que la complejidad y la interrelación están presentes” (pp. 318-320).

En resumen, el currículum ha de convertirse en una herramienta básica con el que aprender a vivir la democracia, hacia dentro y fuera de la escuela. Por tanto, se hace cada vez más necesaria una escuela democrática en contacto con su entorno, en la que se escuche la voz de los estudiantes (Feito, 2010). El ejemplo más significativo lo encontramos en el libro que lleva por nombre "Escuelas Democráticas" donde Michael Apple y James Beane (2005) señalan las condiciones para la existencia de una escuela democrática: i) el libre tránsito de ideas; ii) confianza en la capacidad individual y colectiva de las personas para crear situaciones que permitan resolver los problemas; iii) el uso de la reflexión crítica y del análisis para evaluar ideas, problemas y políticas; iv) preocupación por el bienestar de los demás y el bien común; v) preocupación por los derechos de los individuos y de las minorías; vi) una comprensión de la democracia no tanto como un ideal que deba ser alcanzado sino como un conjunto de valores que deben ser vividos y que deben guiar nuestras vidas y, vii) la organización de las instituciones sociales para promover y extender el modo de vida democrático.

En este tipo de centros se plantea que la cualidad distintiva de los seres humanos es su capacidad de pensar. Se parte de la idea elemental de que no se puede aprender bien lo que no se ha experimentado previamente. El objetivo es "formar personas reflexivas y críticas" (Feito, 2010, p. 76). Popkewitz (1987) subraya que participar en las escuelas es participar en un contexto social que contiene pautas de razón, normas de práctica y concepciones del conocimiento. Un sistema educativo se crea y modifica con el propósito de contribuir a esa capacitación de los niños y niñas para asumir responsabilidades y para poder ser personas autónomas, solidarias y democráticas. Esta meta educativa es lo que debe condicionar la toma de decisiones en la planificación, desarrollo y evaluación del currículum (Torres, 1989). 
Un ejemplo de escuela democrática lo encontramos en Bealings Schools (Gran Bretaña) ${ }^{2}$, una comunidad de aprendizaje donde niños y adultos aprenden juntos. Cada semana se celebra una asamblea en la que los estudiantes (la escuela tiene un total de 100) tienen la oportunidad de participar en la toma de decisiones, proponer puntos del orden del día y votar sobre ellos. Duncan asume la dirección de la escuela desde hace 18 años, creando un centro donde el arte, la poesía, los cuentos, la fascinación por otras culturas, y la música, están presentes en cada rincón. Cuentan con un taller de carpintería. En la escuela se anima a los alumnos a construir ellos mismos en lugar de comprar artefactos costosos, no se fomenta el uso indiscriminado del ordenador, que se ve como una herramienta más, no como el vehículo principal para acceder al conocimiento. Trabajan incorporando el método desarrollado por Dorothy Heathcote, "Mantle of the expert" (la toga del experto). El trabajo que realizan los escolares a través de este método no se evalúa con notas, sino que es el destinatario ficticio (una ONG que protege a los osos, por ejemplo) quien ayuda a los niños a identificar sus puntos fuertes y débiles. Los resultados, según la inspección oficial del gobierno, son un currículum maravilloso impartido por un equipo brillante.

La sociedad en la que nos encontramos propone nuevos sentidos al conocimiento que se enseña, regulaciones muy diferentes de esos contenidos, unas formas de poner en contacto a los aprendices con los contenidos, nuevas fórmulas de control, así como una ruptura de las coordenadas espacio-temporales tradicionales con las que se regulaba un artefacto cultural construido como es el currículum. Quizás estemos viviendo una etapa de cambio, en la que se deja atrás la época del conocimiento especializado y se avanza hacia una sociedad del conocimiento en la cual todas las personas puedan participar en sistemas didácticos generadores de conocimientos aplicables, adecuados a sus expectativas (Izquierdo, 2005). Esto es, que el conocimiento adquiere una nueva cualidad, es moldeable, para que puedan aprenderlo todos los alumnos. Chevellard (1991) se refiere a la clase como a un sistema didáctico, cuyos elementos son los escolares, los docentes y los contenidos; como en todos los sistemas, estos elementos interaccionan y la interacción óptima se produce cuando la acción docente es eficaz y los alumnos aprenden.

En síntesis, de estas ideas extraemos una determinada imagen de la pedagogía:

Un modo de enfocar las relaciones entre adultos y niños y jóvenes, una manera de entender la relación entre las nuevas generaciones y la sociedad y la cultura, una comprensión de lo que supone aprender y crecer, madurar como persona en una sociedad. Una pedagogía que intenta responder a cuáles son las experiencias que necesitan niños y jóvenes para crecer con equilibrio, seguridad y decisión, para poder vivir sus propias vidas con dignidad, con consciencia y con libertad. Una pedagogía que se propone cuidar y fortalecer los recursos personales para afrontar el vivir con deseo, sensibilidad y apertura; que busca proporcionarles espacios, relaciones y experiencias para poder confrontar sus vivencias con otros,

2 Véase Bealing Schools en http://www.bealings.org.uk 
para poder ampliar y contrastar sus visiones y convicciones sobre el mundo, sobre los demás y sobre sí mismos, para poder encontrar los equilibrios entre la vida propia, los propios deseos y necesidades y los de los demás. (Contreras, 2010, pp. 562-563)

\title{
4. Revalorizar el sentido del "Humanities Curriculum Project" para una escuela democrática
}

Salimos al encuentro de un diálogo renovado con las aportaciones pedagógicas y con las ideas subyacentes en las propuestas de un gran diseñador del Currículum: Lawrence Stenhouse. Un planteamiento que confluye junto a otros en la necesidad de renovar la forma en la que el conocimiento es tratado a día de hoy. Descubrir su pensamiento es crucial para comprender el tratamiento del currículum como construcción social y como una hipótesis de acción. Así como, ayudarnos en el desarrollo de estrategias de resistencia y fortaleza en estos tiempos selectivamente conservadores y tradicionalistas. Resistencia que nos remita a:

\begin{abstract}
Mantenerme al otro lado, fuera, y criticarlo pero no de forma negativa: Criticarlo para que los profesores puedan entender, puedan discutir sus implicaciones y cómo el modelo que se les ofrece contrasta con sus visiones sobre la educación. De forma puedo contribuir a crear algún espacio desde el que los profesores podrán transformar este sistema. (John Elliot, citado en Sancho y Hernández, 1989, p. 81)
\end{abstract}

El Humanities Curriculum Project fue uno de los planes más controvertidos e influyentes del movimiento de desarrollo curricular del Reino Unido. Un proyecto de tal envergadura incluiría preocupaciones en torno al: derecho a saber del alumno y de la alumna (la esencia de la educación consiste en proporcionar acceso al conocimiento como un medio y una disciplina de reflexión. Es decir, la enseñanza facilita la comprensión de lo que debe ser aprendido), la conexión del conocimiento escolar con el mundo extraescolar del estudiante y la importancia del diálogo como manera de analizar las ideas en colaboración. La finalidad de este proyecto en palabras del propio Stenhouse (1991) es: "educar para tensiones interraciales y malestar dentro de nuestra sociedad - la cual es y será multirracial-socavando los prejuicios, desarrollando el respeto hacia variadas tradiciones y animando a la comprensión mutua, la sensatez y la justicia" (pp. 181-182).

Una de sus máximas radicó en una reorganización de los contenidos curriculares en torno a temas conflictivos de la vida diaria, argumentando que no podía existir desarrollo del currículum sin desarrollo del profesor, lo que implicaba fomentar el desarrollo de las capacidades reflexivas del docente. Cree en un docente que investiga sobre su práctica en aras de mejorarla y en el análisis de la realidad educativa 
con vistas a su transformación. Al tiempo que acuña la necesidad de tratar en la acción educativa las cuestiones que son controvertidas; esta forma de investigación en áreas controvertidas ha de estar constituida por el diálogo y no por la instrucción.

Entre sus principios de procedimiento, Stenhouse (1991) sostiene que debemos:

- Ayudar a los alumnos a tomar conciencia de sus propias actitudes.

- Contribuir a que detecten desviaciones y los motivos existentes tras las mismas.

- Favorecer el que se percaten del contenido emocional existente en las tensiones o conflictos interraciales.

- Poner claro los factores históricos y sociales que ayudan a explicar la presencia de grupos étnicos en la sociedad.

- Ayudar a los alumnos a que ver que muchos problemas que parecen proceder de causas raciales pueden ser predominantemente sociales.

- Procurar que consideren la posibilidad de una organización para el cambio. (pp. 181-182)

Un ejemplo práctico para entender estos temas conflictivos y el procedimiento del proyecto; son los que se plantean los y las adolescentes del Washington International School Ms French Humanities de los Estados Unidos ${ }^{3}$ :

- ¿Cuáles son los orígenes y los aspectos principales de la religión rastafari?

- ¿Cómo la guerra de las drogas en México, afecta a los pueblos y ciudades fronterizas entre México y los Estados Unidos?

- ¿Cómo el régimen del dictador Stroessner en Paraguay es similar a regímenes de dictaduras Europeas en este momento?

Los y las estudiantes se enfocan en un problema particular para verlo $\mathrm{u}$ observar desde una perspectiva diferente con el propósito de crear sus propias conclusiones basadas en la investigación realizada. Para ello, han de saber manejar la gran cantidad de información que está a su disposición en Internet, sabiendo identificar las fuentes principales; incluidas fuentes de procedencia local. Sus hipótesis de trabajo van en consonancia de problemáticas sociales y culturales que afectan a determinados grupos de personas. La búsqueda y la explicación de los fenómenos sirven de nutrientes para el currículum humanístico.

3 Véase el documental https://www.youtube.com/watch?v=GrO6a-F1yFU 
El Humanities Currículum Project, por tanto, cree en el diseño de un currículum que pueda dar respuesta a las múltiples necesidades del alumnado, con una particularidad, que sea un currículum gestado desde la propia institución educativa, generado desde abajo. Un proyecto curricular desde el compromiso pedagógico docente, implementado y autoevaluado en los centros, como un proceso cíclico construido desde la acción. Desde su posición ante el tratamiento cultural, reconocemos su influencia positiva en el trato de la diversidad cultural. Toda propuesta curricular tiene que estar apoyada en la cultura de procedencia del alumnado (Torres, 1996), acercando los problemas de la vida cotidiana y las preocupaciones personales como ejes primordiales de la armadura curricular. El Proyecto Curricular de Stenhouse, se muestra ideológicamente conectado, a nuestro modesto parecer, con la filosofía de las escuelas antirracistas y democráticas, en el que el papel del profesorado se torna esencial. Los y las docentes con sensibilidad y compromiso social y político con colectivos oprimidos, silenciados y marginados, demuestran con su práctica la injustica de muchos de los estereotipos negativos acerca de las posibilidades de aprender y de tener éxito en las tareas de aprendizaje (Torres, 1996). Desde esta posición se necesita el rearme del profesorado con miras a ejercer un papel fundamental en el desarme del etnocentrismo, el racismo, el sexismo, la xenofobia... desde la propia acción educativa, generando, por el contrario, procesos de interculturalidad y la promoción de espacios inclusivos y democráticos.

\section{A modo de epílogo: tesis para su introducción e implantación en la escuela actual}

Está claro que la escuela actual necesita aires renovados y frescos. Una escuela que se desvincule de una sociedad, que en tiempos anteriores, parecía estar condenada al fracaso, bajo un paraguas conservadurista y tradicionalista. Partimos, por tanto, de un presente marcado por las siguientes ideas (Sancho y Hernández, 2004): el colectivo docente es valorado por su rol de transmisor de conocimientos de forma parcelada (disciplinaria), al alumnado se le considera como responsable de sus fracasos. Todo ello, al cobijo de un eslogan básico: premiar la cultura del esfuerzo. Un currículum compartimentalizado, donde el conocimiento académico sigue teniendo una fuerte presencia. Una evaluación, a veces humillante, desligada del bagaje experiencial del alumnado y de su propio ritmo de aprendizaje. Un equipo directivo sometido a una fuerte presión burocrática y un colectivo docente que lo padece. Y, una Administración, centralizada y burocratizada. Aunque estas consideraciones se realizaron en el 2004 a día de hoy estos problemas siguen imperando. Es por ello que el tratamiento del currículum que aquí ofrecemos puede ser una excelente alternativa a la mejora educativa, ¿qué proponemos?:

En primer lugar, proponemos para su implantación, la emergencia de un equipo directivo que crea e impulse el cambio. Cuando las reformas o las innovaciones se engendran de abajo-arriba, contextualizada al marco socio-cultural en el que se ubica la institución educativa, se genera un mayor compromiso 
pedagógico entre el colectivo docente. Un equipo directivo que promueva una cultura escolar con tintes democráticos y dialógicos, que reestructure su proyecto educativo en base a los principios de un curriculum democrático, humanístico, inclusivo e integrador. Un equipo directivo que se fundamente en un liderazgo distribuido-compartido (Moral, Amores y Ritacco, 2016), donde el protagonismo no resida únicamente en el director o la directora. Un equipo directivo que redefina metas y objetivos, que apueste por la evaluación formativa, que promueva la investigación-acción (Hopkins et al., 2014) y comprometido por un modelo centrado en el aprendizaje del alumnado. No obstante, bajo este marcado ideal, nos encontramos la "otra cara de la moneda", la presión burocrática a la que se encuentran sometidos los centros educativos o la preocupación exacerbada (por presión externa) hacia las pruebas de evaluación estandarizadas, así como el papel otorgado a la directora o al director desde la promulgación de la Ley Orgánica 8/2013, de 9 de diciembre, para la mejora de la calidad educativa (LOMCE).

En segundo lugar, proponemos (tal como lo hacía el propio Stenhouse) que los y las docentes se presten a la investigación sobre su propia práctica con el afán de mejorarla y de retroalimentarla. Unos y unas docentes abiertos a la cooperación, a la colaboración y a la evaluación. Un colectivo docente que se muestre receptivo al arte de enseñar, teniendo en cuenta al alumnado. Un colectivo docente que torne su mirada hacia las nuevas demandas de un estudiantado que nos lo reclama. Unos y unas docentes que piensen en un aula activa donde la participación, la reflexión, la deliberación compartida se convierta en los ingredientes que la nutran. Un profesorado que diseñe sus propuestas de acción educativa desde el tratamiento de temas controvertidos y cercanos a la realidad del alumnado. Que apuesten por la atención a la diversidad desde la inclusión, que revisen progresos para alcanzar logros significativos.

Todo ello al amparo de una comunidad educativa que apoye el proceso y participe de su implementación de forma coordinada. Las instituciones educativas no deben convertirse en cotos privados para el profesorado, como tradicionalmente se han venido considerando. Ha quedado demostrada que la implicación activa de la comunidad educativa en las cuestiones escolares tiene un enorme peso en el cambio de cualquier institución, evitando problemas tales como: el absentismo y el fracaso escolar. La necesidad de crear redes de colaboración y de acción como apoyos para el proceso de mejora.

\section{Referencias}

Apple, M. y Beane, J. (2005). Escuelas democráticas. Madrid: Morata.

Ausubel, D. (2002). Adquisición y retención del conocimiento. Barcelona: Paidós.

Bauman, Z. (2006). Modernidad líquida. Buenos Aires: Fondo de Cultura Económica. 
Bernstein, B. (1996). Pedagogía, control simbólico e identidad. Madrid: Morata.

Ceberio, M. y Watzlawick, P. (1998). La construcción del universo. Conceptos introductorios y reflexiones sobre epistemología, constructivismo y pensamiento sistémico. Barcelona: Herder.

Chevallard, Y. (1991). La transposition didactique. Du savoir savant au savoir enseigné. (2a ed.). Grenoble, Francia: La Pensée Sauvage, Editions.

Contreras, J. (2010). Ser y saber en la formación didáctica del profesorado: una visión personal. Revista Interuniversitaria de Formación del Profesorado, 61-81. Recuperado de http:// www.redalyc.org/articulo.oa?id=27419198004

Cook-Sather, A. (2007). Resisting the impositional potential of student voice work: Lessons for liberatory educational research from poststructuralist feminist critiques of critical pedagogy. Discourse, 28 (3), 389-403.

Darling-Hammond, L. (2001). El derecho de aprender. Crear buenas escuelas para todos. Barcelona: Ariel.

Dewey, J. (1989). Democracia y Educación. Buenos Aires: Losada.

Feito, R. (2010). Familias y escuela. Las razones de un desencuentro. Educación y Futuro, 22, 87-107.

Feito, R. (2011). Los retos de la participación escolar. Elección, control y gestión de los centros educativos. Madrid: Morata.

Fernández Enguita, M. (2001). Educar en tiempos inciertos. Madrid: Morata.

Feuerstein, R. (2006). Instrumental Enrichment. Jesuralem: ICEL Publications.

Freinet, C. (1970). Técnicas Freinet de la escuela moderna. México: Siglo XXI Editores.

García, F.F. (2007). El conocimiento cotidiano como referente del conocimiento escolar. Las competencias profesionales para la enseñanza-aprendizaje de las ciencias sociales ante el reto europeo y la globalización (pp. 481-498). Bilbao: Asociación Universitaria de Profesorado de Didáctica de las Ciencias Sociales.

García, F.F. (2001). El conocimiento escolar en una didáctica crítica. En J. Mainer (coord.), Discursos y prácticas para una didáctica crítica. Ideas y líneas de trabajo para transformar la enseñanza (pp. 119-139). Sevilla: Díada. 
García-Lastra, M. (2013). Educar en la sociedad contemporánea. Hacia un nuevo escenario educativo. CONVERGENCIA. Revista de Ciencias Sociales, 62, 199-220.

Giddens, A. (2005). Un mundo desbocado. Los efectos de la globalización en nuestros días. Madrid: Taurus.

Gimeno Sacristán, J. (2008). El currículum como texto de la experiencia. Quaderns digitals: Revista de Nuevas Tecnologías y Sociedad, 51.

Gimeno Sacristán, J. (2005). La educación que aún es posible. Ensayos acerca de la cultura para la educación. Madrid: Morata.

Gimeno Sacristán, J. (coord.) (2010). Saberes e incertidumbres sobre el currículum. Madrid: Morata.

Hernández, F. y Sancho, J. Ma (1989). Para enseñar no basta con saber la asignatura. Barcelona: Laia. Cuadernos de Pedagogía.

Hernández, G. y Díaz, F. (2013). Una mirada psicoeducativa al aprendizaje: qué sabemos y hacia dónde vamos. Sinéctica, 40.

Hopkins, D. et al. (2014). School and system improvement: a narrative state-ofthe-art review. School Effectiveness and School Improvement, 25(2), 257-281.

Izquierdo, M. (2005). Hacia una teoría de los contenidos escolares. Enseñanza de las Ciencias, 23 (1), 111-122.

Klafki, W. (1958). Didaktische Analyse als Kern der Unterrichtsvorbereitung. Basel: Wienheim.

Ley Orgánica 8/2013, de 9 de diciembre, para la mejora de la calidad educativa. Boletín Oficial del Estado, de 10 de diciembre de 2013, núm. 295, pp. 97858-97921.

Luque, A., Ortega, R. y Cubero, R. (1997). Concepciones constructivistas y práctica escolar. En M. J. Rodrigo y J. Arnay (Comps.). La construcción del conocimiento escolar (pp. 313336). Barcelona: Paidós

Macionis, J. y Plumer, K. (1991). Sociología. Madrid: Prentice Hall Internacional.

Martínez Bonafé, J. (2004). Definición de Currículum Democrático en F. Salvador, J. Rodríguez y A. Bolívar, (direc.), Diccionario Enciclopédico de Didáctica (pp.316-320). Volumen I. Málaga: Aljibe. 
Martínez, J.B. (2010). El currículum como espacio de participación. La democracia escolar ¿es posible? En J. Gimeno Sacristán (Coord.), Saberes e incertidumbres sobre el currículum (pp. 162-179). Madrid: Morata.

Moral, C., Amores, F.J. y Ritacco, M. (2016). Liderazgo distribuido y capacidad de mejora en centros de educación secundaria. Estudios sobre educación, 30, 115-143.

Ordine, N. (2013). La utilidad de lo inútil. Barcelona: Acantilado.

Perkins, D. (2010). El aprendizaje pleno. Buenos Aires: Paidós.

Popkewitz, T. S. (1987). The formation of school subjects and the political context of schooling. In T. S. Popkewitz (Ed.), The formation of school subjects: The struggle for creating an American institution (pp. 1-25). London: Falmer Press.

Pozo, J.I. (2008). Aprendices y maestros: la psicología cognitiva del aprendizaje. Madrid: Alianza

Pozuelos, F.J.; Romero, D.; García, F.J. y Morcillo, V. (2010). No basta con soñar otra escuela, hay que hacerla. Relatos de experiencias y un caso. Investigación en la Escuela, 70, 5-20.

Rozada, J.Mª (2001). Ideas para una didáctica crítica del conocimiento social. Trabajadores de la Enseñanza: Monográfico La enseñanza de las ciencias sociales en Asturias. Materiales para el desarrollo curricular, 8.

Sancho, J.M y Hernández, F. (2004). ¿Por qué no ha fructificado la propuesta del profesor como investigador? Y algunas propuestas para resistir a un presente nostálgico. Educar, 34, $39-51$.

Sancho, J.M y y Hernández, F. (1989). Entrevista a John Elliot. De la autonomía al centralismo. Cuadernos de Pedagogía, 172, 75-81.

Stenhouse, L. (1991). Investigación y desarrollo del currículum (3ª edición). Madrid: Morata.

Thiessen, D. y Cook-Sather, A. (Eds.) (2007). International Handbook of Student Experience in Elementary and Secondary Schools. The Netherlands: Springer.

Torres, J. (1989). Libros de texto y control del currículum. Cuadernos de Pedagogía, 235, 68-69.

Torres, J. (1996). Educación Antirracista: Diversidad y justicia social en las aulas. En B. Zufiaurre (Coord.), Comprensividad, desarrollo productivo y justicia social (pp. 209-246). Barcelona: Icaria. 
Torres, J. (2005). Educación Infantil y Derechos de la Infancia. Aula de Infantil, 24, 38-44.

Torres, J. (2010). La justicia curricular. El caballo de Troya de la cultura escolar. Madrid: Morata.

UNESCO (2015). Desglosar el Objetivo de Desarrollo Sostenible 4 Educación 2030. Educación 2030.

Velasco, A. (2007). Un sistema para el análisis de la interacción en el aula. Revista Iberoamericana de Educación, vol. 42, 3, 1-12.

Villalta, M.A., Assael, C. y Martinic, S. (2013). Conocimiento escolar y procesos cognitivos en la interacción didáctica en la sala de clase. Perfiles educativos, 35(141), 84-96.

Villalta, M. y Martinic, S. (2009). Modelos de estudio de la interacción didáctica en sala de clase. Revista Investigación y Postgrado, vol. 24, 2, 61-76. 
Repensando el Currículum desde una visión integrada: "El Humanities Curriculum Project" para una escuela democrática" 